\title{
Author Correction: Revealing the complex genetic structure of cultivated amaryllis (Hippeastrum hybridum) using transcriptome- derived microsatellite markers
}

\author{
Yi Wang, Defeng Chen, Xiaofeng He, Jiangxian Shen, Min Xiong, Xian Wang, Di Zhou \& \\ Zunzheng Wei
}

Correction to: Scientific Reports https://doi.org/10.1038/s41598-018-28809-9, published online 13 July 2018

The Article contains errors.

The Article reports cultivars 'Chico' and 'Jewel' as double petal. It was brought to the authors' attention that this information may be incorrect. To confirm the correct assignment, the authors replanted the cultivars used in the study and recorded their phenotypic characteristics again, including flower colour and petal type. These results confirmed that 'Chico' is a single petal, 'Jewel' is a semi-double petal, and 'Blushing Bride' is a single petal cultivar.

Therefore, in the Results subsection 'The genetic relationships and population structure of cultivated amaryllis',

"It is also noteworthy that the accessions within each cluster can also be described on the basis of their petal number (single or double) and colour, including 'Chico' and 'Ballerina' (both with double pink or red flowers) along with 'Papillo,' 'La Paz,' 'Exotic star,' 'Santiago,' 'Fairy tale, and 'Faro' (single petals) in cluster I'.

should read:

"It is also noteworthy that the accessions within each cluster can also be described on the basis of their petal number (single or double) and colour, including 'Ballerina' (double red flowers) along with 'Chico, 'Papillo, 'La Paz', 'Exotic star,' 'Santiago, 'Fairy tale', and 'Faro' (single petals) in cluster I'.

and,

“These accessions are distinct from 'Benfica' and 'Cherry Nymph' (double petals); 'Bolero' and 'Faro' (single and pink or red flowers); 'Brazza' and 'Adele' (single and red flowers); and 'Amigo', 'Gervase', 'Amorize, '13-47', 'Red Lion', 'Double Dream' (single or double and pink or red) in cluster II. All of these varieties are distinct from '1032' and '10-6' (double, red and white complex colour), which group with 'Pasadena, 'Splash', 'Jewel,' 'Harlequin', 'Ice Queen', 'Zombie, 'Vegas', 'Ragtime', and 'First Love' (double peals) in cluster III."

should read:

“These accessions are distinct from 'Benfica' and 'Cherry Nymph' (double petals); 'Bolero' and 'Faro' (single and pink or red flowers); 'Brazza' and 'Adele' (single and red flowers); and 'Amigo, 'Gervase', 'Amorice, '13-47', 'Red Lion,' 'Double Dream' (single or double and pink or red) in cluster II. All of these varieties are distinct from ' $10-$ 32' and '10-6' (double, red and white complex colour), which group with 'Pasadena, 'Splash', 'Jewel', 'Harlequin', 'Ice Queen', 'Zombie, 'Vegas', 'Ragtime', and 'First Love' (semi-double or double peals) in cluster III.' 
In addition, in the Discussion subsection 'Cluster analysis and genetic structure within Hippeastrum spp. accessions',

"However, the N-J tree and structural plot generated in this study (Fig. 4) demonstrate that the 104 accessions we considered cannot be fully clustered according to the number of flowers or their colour. Exceptions include the 'Lemon sorbet', 'Ballerina' and 'Chico' varieties. Of these varieties, the former possesses green single petals, whereas 'Ballerina' (red flowers) and 'Chico' (pink flowers) both have double petals. These exceptions are important because they illustrate the comprehensive nature of amaryllis population structure.”

should read:

"However, the N-J tree and structural plot generated in this study (Fig. 4) demonstrate that the 104 accessions we considered cannot be fully clustered according to the number of flowers or their colour, which illustrate the comprehensive nature of amaryllis population structure."

Finally, the corrected section of Supplementary Table 5, listing the characteristics of the affected cultivars, is included below as Table 1 .

\begin{tabular}{|l|l|l|l|}
\hline Cultivars/hybrids & Origins & Spathe Color & Type \\
\hline Chico & Netherlands & pink & single petal \\
\hline Jewel & Netherlands & white & semi-double petal \\
\hline Blushing Bride & South Africa & pink & single petal \\
\hline
\end{tabular}

Table 1.

There are also several typographical errors in some of the names. Cultivar 'Amorize' should be 'Amorice', and $H$. solandrifoliu should be $H$. solandrifolium.

These changes do not affect the overall conclusions of the Article.

(c) (i) Open Access This article is licensed under a Creative Commons Attribution 4.0 International License, which permits use, sharing, adaptation, distribution and reproduction in any medium or format, as long as you give appropriate credit to the original author(s) and the source, provide a link to the Creative Commons license, and indicate if changes were made. The images or other third party material in this article are included in the article's Creative Commons license, unless indicated otherwise in a credit line to the material. If material is not included in the article's Creative Commons license and your intended use is not permitted by statutory regulation or exceeds the permitted use, you will need to obtain permission directly from the copyright holder. To view a copy of this license, visit http://creativecommons.org/licenses/by/4.0/.

(c) The Author(s) 2020 